\title{
KOAH Tanılı Yaşı Bireylerde Pulmoner Rehabilitasyon
}

\section{Pulmonary Rehabilitation in Elderly Individuals with COPD}

\author{
Tahir Keskin $^{1 *}$, Zeliha Başkurt $^{2}$ \\ ${ }^{1}$ Süleyman Demirel Üniversitesi Sağlık Bilimleri Fakültesi Fizyoterapi ve Rehabilitasyon Bölümü, Isparta, Türkiye \\ e-mail: tahirkeskin2323@gmail.com, zelihatulum@gmail.com \\ ORCID: 0000-0002-9237-3300 \\ ORCID: 0000-0001-7488-9242 \\ *Sorumlu yazar/ Corresponding Author: Tahir Keskin \\ Gönderim Tarihi / Received: 30.06 .2020 \\ Kabul Tarihi / Accepted: 23.11.2020 \\ DOI:10.34087/cbusbed.760603
}

\begin{abstract}
$\ddot{\mathbf{O z}}$
Kronik obstrüktif akciğer hastalığı (KOAH) yüksek morbidite ve mortalite oranları olan, yaşlı popülasyonda yaygın olarak görülen ve prevalansı yaşla birlikte artan kronik respiratuar bir problemdir. Yaşlı nüfus oranının dünya genelinde artmasıyla birlikte KOAH özellikle gelişmiş ülkelerde majör bir halk sağlığı problemi olmuştur ve en yüksek mortalite nedenleri arasında yer almaktadır. Yaşa bağlı olarak akciğerlerde meydana gelen fizyolojik değişiklikler ve çevresel faktörler nedeniyle KOAH prevalansı yaşlılarda yüksektir. Pulmoner rehabilitasyon ve inhaler farmakolojik ajanlar, KOAH'lı yaşlıların bireysel tedavisinde önemli bir yere sahiptir. Pulmoner rehabilitasyon yaşlılarda fonksiyonel egzersiz kapasitesinin ve sağlıkla ilgili yaşam kalitesinin geliştirilmesinde; dispnenin, sağlık hizmetlerinin kullanımı ve sağlık maliyetlerinin azaltılmasında etkindir. Yapılan çalışmalar KOAH'lı yaşlı bireylerin, pulmoner rehabilitasyondan genç hastalar kadar fayda görmekte olduğunu, dolayısıyla yaşın pulmoner rehabilitasyon için bir dışlama kriteri olmadığını göstermektedir. Hastalığın akut alevlenme dönemlerinde bile yaşlılarda pulmoner rehabilitasyonun etkin olduğu görülmüştür. $\mathrm{Bu}$ derlemede $\mathrm{KOAH}$ tanısı olan yaşlı bireylerde pulmoner rehabilitasyonun bileşenleri olan aerobik ve dirençli egzersizler, respiratuar kas kuvvet eğitimi, diafragmatik solunum ve fiziksel aktivitenin etkinliği güncel literatür ışı̆̆ında tartışılacaktır.
\end{abstract}

Anahtar Kelimeler: KOAH, yaşl1, pulmoner rehabilitasyon, pulmoner fizyoterapi

\begin{abstract}
Chronic obstructive pulmonary disease (COPD) is a chronic respiratory problem with high morbidity and mortality rates and common in the elderly population with increasing prevalence by aging. COPD is among the highest causes of mortality and has been a major public health problem, especially in developed countries, as the elderly population increases worldwide. The prevalence of COPD is high in the elderly due to age-related physiological changes in the lungs and environmental factors. Pulmonary rehabilitation and inhaler pharmacological agents play an important role in the individual treatment of the elderly with COPD. Pulmonary rehabilitation is effective in improving functional exercise capacity and health-related quality of life; reducing dyspnea, the use of health services and health costs in the elderly. Studies have shown that elderly individuals with COPD benefit from pulmonary rehabilitation as much as younger patients, and therefore age is not an exclusion criterion for pulmonary rehabilitation. Even in acute exacerbations, pulmonary rehabilitation is effective in the elderly. In this review; aerobic and resistant exercises, respiratory muscle strength training, diaphragmatic respiration and physical activity, the components of pulmonary rehabilitation in elderly individuals with COPD, will be discussed in the light of the current literature.
\end{abstract}

Keywords: COPD, elderly, pulmonary rehabilitation, pulmonary physiotherapy

1. Giriş

Kronik obstrüktif akciğer hastalığı (KOAH) yaşlı popülasyonda sıkça görülen, morbidite ve mortalitenin başlıca nedenleri arasında sayılan, hava yollarında ve akciğerde zararlı partiküllere veya gazlara artan kronik inflamatuar yanıtla ilişkili olan ve sürekli hava akımı sınırlaması ile karakterize önlenebilir ve tedavi edilebilir hastalıktır [1-3]. Dünya genelinde KOAH prevalansı göz önüne alındığında hastalığın ne denli tehlikeli boyutlara ulaştığı görülebilir. 1990- 2010 yılları arasında KOAH'lı 
olgu sayısı ciddi düzeyde artış göstermiş ve 384 milyona kadar yükselmiştir [4]. Tanısı konulmamış popülasyon da düşünüldüğünde KOAH prevalansının daha da ciddi boyutlara ulaşabileceği belirtilmektedir [1]. Ülkemizde ise 40 yaş üzeri yetişkinlerde $\mathrm{KOAH}$ prevalansının $\% 19,1$ olduğu bildirilmiştir [5]. KOAH prevalansı yaşla birlikte artış göstermektedir [1]. Yaşlı popülasyonun toplam nüfus içindeki artış oranı dikkate alındığında gelecekte KOAH'a bağlı ortaya çıkacak problemlerin daha da artacağ 1 düşünülmektedir. Yaşla birlikte akciğerlerde; ventilasyon ve difüzyon kapasitesinde azalma, elastik recoil kaybı, zorlu ekspiratuar akış, solunum kas gücü ve göğüs kafesi mobilitesindeki azalma gibi değişiklikler meydana gelmektedir [6]. Bununla birlikte KOAH ve eşlik eden inflamasyonun akciğer yaşlanmasını provoke ettiği ve komorbiditeleri arttırdığ meydana gelen fizyolojik değişiklikler, oksidatif strese neden olarak DNA hasarını tetikleyen sigara kullanımı, biyokütle dumanına maruz kalma ve mesleki faktörler kademeli olarak KOAH'1 tetikler ve bu gibi faktörler $\mathrm{KOAH}$ prevalansının yaşlılarda yüksek olmasını açıklar niteliktedir [8].

KOAH gelişimi multifaktöriyel olup oluşumunda hem çevresel hem de genetik etmenlerin büyük rolü vardır. Genetik faktör olarak alfa-1 antitripsinin kalıtsal olarak eksikliğinin $\mathrm{KOAH}$ gelişiminde rol oynadığı fakat KOAH'ın daha çok çoklu genetik bir hastalık olduğu belirtilmektedir [9]. KOAH gelişiminde en büyük rolü olan çevresel etmen ise sigaradır. Sigara içenlerin içmeyenlere göre, içmeyen kişilerde ise çevresel tütün dumanına maruz kalanlarda KOAH prevalansının yüksek olduğu bildirilmiştir [2,10]. Sigaranın yanında mesleki toz ve kimyasallara maruz kalmak ve iç ortamdaki hava kirliliği de KOAH prevalansını arttıran çevresel etmenler arasında gösterilebilir. Enfeksiyonlar, beslenme bozuklukları ve kötü sosyoekonomik durum diğer risk faktörleri arasındadır [10]. Tüm bu risk faktörlerinin etkileşimi ile KOAH'ın oluştuğu belirtilmektedir.

KOAH'lı olgularda öksürük ve balgam klinik semptomlar arasında yer almakla birlikte en belirgin klinik semptomun dispne olduğu bildirilmektedir. Yaşa bağlı fizyolojik değişiklikler ve kırılganlık nedeniyle fiziksel aktivite seviyelerinde azalmalar meydana gelir. Azalan fiziksel aktivite ile birlikte gelişen dekondisyon, ventilasyon kalitesinin düşmesine sebep olur ve bu durum dispnenin giderek artmasına neden olan bir kısır döngü haline gelir [11]. Öksürük, balgam üretimi, hırıltılı solunum ve göğüste sıkışma nonspesifik KOAH semptomları arasında yer almaktadır [1].

KOAH için yaygın olarak kullanılan spirometrik kriter "Global Initiative for Chronic Obstructive Lung Disease" (GOLD) tarafından önerilen post bronkodilatör FEV1/ FVC değerinin 0,7'nin altında olmasıdır. Bu sabit oran yöntemi FEV1/ FVC değerinin yaşla azalması nedeniyle $\mathrm{KOAH}$ prevalansını yaşlılarda olması gerekenden yüksek, gençlerde ise düşük göstermektedir[12-14]. Bu nedenle referans popülasyonun \% 5 altında olan FEV1 / FVC oranı alınarak farklı bir istatistiksel yöntem (LLN) geliştirilmiştir. $\mathrm{Bu}$ iki yöntemi karşılaştıran bilimsel kanıtların yetersiz oluşu nedeniyle hangi yöntemin KOAH tanısı için en uygun olduğu belirsizdir ancak yaşlı popülasyonu referans alan LNN yönteminin yaşlılarda KOAH tanısı için kullanımı tavsiye edilmektedir (1). Spirometrik testleri tamamlayamayan yaşlılarda tanının klinik yöntemlerle konması; 55 yaş üzeri sigara öyküsü olanlar ve oskültasyonda hışıltılı solunumu olan yaşlıların $\mathrm{KOAH}$ şüphesi ile ayrıntılı değerlendirilmesi gerekmektedir $[15,16]$.

\subsection{Yaşlılarda KOAH ve Yaygın Geriatik Sendromlar}

İskelet kası disfonksiyonu KOAH hastalarında sıklıkla görülen problemlerden biridir. 50 yaşın üzerindeki KOAH hastalarında, kas kütlesinde yılda \%1-2'lik bir azalma görülmekte ve bu azalma 60 yaş sonrasında \% 3'lere çıkmaktadır. Sarkopeni olarak bilinen bu fenomen, kırılganlık sendromunun önemli bir göstergesidir. Sarkopeninin 65 yaşın üzerindeki tüm bireylerin yaklaşık \%5-13'ünde, KOAH'lı hastaların ise \%15-40'1nda görüldüğü rapor edilmiştir $[17,18]$. KOAH'l1 yaşlılarda sarkopeni; akciğer fonksiyonundan bağımsız olarak kuadriseps kas güçsüzlüğü, atrofi, tip II liflerin yapısal değişimi ve kötü prognozla ilișkilidir. Sarkopeni görülmeyen yaşlılara göre sarkopenik yaşlılarda egzersiz kapasitesi, fonksiyonel performans ve fiziksel aktivite düzeylerinin düşük olduğu görülmüştür [18].

KOAH; yaşlanma, sigara içme, inflamasyon ve endokrin disfonksiyon gibi ortak risk faktörleri nedeniyle kırılganlıkla yakından ilişkilidir. KOAH'lı yaşlılarda kırılganlık prevalansinın (\%10,2) KOAH tanısı olmayanlara göre $(\% 3,4)$ anlamlı düzeyde yüksek olduğu belirtilmiştir [19]. Kırılganlık semptomu olan yaşlıların, kırılgan olmayanlara göre fonksiyonel yetersizlik, günlük yaşam aktivitelerinde bağımlılık ve mortalite oranları yüksektir [19,20]. Kırılganlık KOAH'ın gelişimi ve ilerlemesi için bağımsız bir risk faktörüdür. Aynı zamanda KOAH da kırılganlığa yol açabilir; dolayısıyla birini tedavi etmek, diğerinin de tedavisi anlamına gelebilir. KOAH'lı hastalarda kırılganlığın erken dönemde belirlenmesi ve değerlendirilmesi müdahale seçimini etkileyebilir ve tedavinin etkinliğini artırabilir [20].

\subsection{Yaşlılarda KOAH Tedavisi}

Yaşlilarda KOAH tedavisi belirli aşamalardan oluşmaktadır. Öncelikli olarak hastalığın önlenmesi amaçlanmalıdır ve bu aşamada sigarayı bırakma ve aşılanma gibi önlemler alınmalıdır. Yapılan randomize kontrollü çalışmalarda grip aşısının KOAH'lı yaşlılarda solunum yolu enfeksiyonları ve mortalite ile ilişkili komplikasyonları ve hastalık şiddeti ne olursa olsun influenza virüsüne bağlı akut solunum yolu enfeksiyonu insidansını azalttığı bildirilmiştir [21]. KOAH tedavisinin en önemli aşaması ise pulmoner rehabilitasyon (PR) ve pulmoner fizyoterapidir. $\mathrm{Bu}$ uygulamaların KOAH'lı yaşlılarda semptomları azalttığı, egzersiz toleransını ve fiziksel aktivite düzeyini arttırdığ 1 ve günlük yaşam aktivitelerinde bağımsızlığı kazandırdığı belirtilmektedir [1]. Aynı zamanda yapılan çalışmalar, PR'nin yaşlılarda uzun dönem pulmoner 
foksiyon, yaşam kalitesi, egzersiz kapasitesi ve fonksiyonellik üzerinde pozitif terapötik etkiye sahip olduğunu göstermektedir [22]. KOAH hastaları dispne ve kas yorgunluğu nedeniyle egzersiz yapmayı bırakabilir. $\mathrm{Bu}$ nedenle, pulmoner fizyoterapi PR programlarının vazgeçilmez bir bileşenidir.

\subsection{Pulmoner Rehabilitasyon}

Amerikan Toraks Derneği ve Avrupa Solunum Derneği, PR'yi eğitim, davranışsal değişiklikler ve egzersiz eğitimini içeren kapsamlı bir müdahale olarak tanımlamaktadır [23]. KOAH'lı yaşlılar dispne ve yorgunluk nedeniyle fiziksel olarak inaktif duruma gelebilmekte, eşlik eden komorbiditeler prognozu daha da kötü hale getirebilmektedir. Ancak komorbidite varlığının; egzersiz kapasitesinin, semptomların ve yaşam kalitesinin potansiyel iyileşmesini sınırlamadığ gösterilmiştir [24]. Ayrıca KOAH'lı yaşlı bireylerin, PR'den genç hastalar kadar fayda gördüğü dolayısıyla yaşın PR için bir dışlama kriteri olmadığ [25]. Bu nedenle KOAH'lı yaşlılar PR programına katılmaya teşvik edilmelidir.

Yaşlılarda PR yaklaşımı şu başlıklar altında toplanabilir;

$>$ Farmakolojik tedavi,

> Eğitim, beslenme ve psikolojik destek,

> Maksimum egzersiz kapasitesini arttırmak, dispneyi azaltmak ve yorgunluğu azaltmak için üst ekstremite egzersiz eğitimi,

$>$ Diyaframın solunum koordinasyonunu ve inspiratuar kas gücü artırmak, öksürük sıklığını, dispneyi ve hipoksemi semptomlarını azaltmak ve balgam klirensini kolaylaştırmak için büzük dudak solunumu.

$>$ Kardiyopulmoner fonksiyonları geliştirmek için koşu bandı egzersizleri ve alt ekstremite kaslarını geliştirmek için dirençli egzersizler,

> Havayolu temizleme teknikleri (perküsyon, postüral drenaj gibi) ile balgam söktürme,

> Sigarayı bırakma, eğitim ve kişisel sağlık yönetimi [23].

Yaşlılarda KOAH'ın medikal tedavisinde kullanılan başlıca farmakolojik ajanlar kısa ve uzun etkili beta-2 seçici adrenerjik agonistler, kısa ve uzun etkili kolinerjik antagonistler ve kortikosteroidlerdir. Kullanılacak farmakolojik ajana FEV1/FVC oranına, dispne şiddetine ve atak sayısına göre karar verilir. Bu konuda yaşlı bireyleri hedef alan herhangi bir spesifik çalışma olmadığı için standardize bir farmakolojik tedavi bulunmamaktadır [1].

Hasta eğitiminin $\mathrm{KOAH}$ yönetiminde önemli bir rolü vardır. Tanı anında başlayıp tedavinin her aşamasında uygulanması gereken bu özyönetim eğitimi; davranış değişikliği yoluyla hastalık kontrolünü sağlayan ve hastalıkla ilgili spesifik becerileri öğretmeyi amaçlayan hasta eğitim programını ifade eder. Amacı tedaviye bağlılığın artması ve klinik sonuçların iyileşmesidir. Bu nedenle eğitim programlarının içeriğinde alevlenmelerin erken tanınması ve tedavisi, ilaçların uygun kullanımı, yaşamını hastalıkla idame etrme, solunum stratejileri ve sekresyon temizleme teknikleri mutlaka yer almalıdır. Ayrıca KOAH'a bağlı ölümlerin yaklaşık \%20'si sigara kullanımına bağlı olduğu için KOAH'lı yaşlılarda sigara kullanımını önleme konusunda eğitim verilmesi gerektiği belirtilmektedir [1,26].

KOAH'lı yaşlılarda azalmış solunum ve alt ekstremite kas kuvveti azalmış egzersiz kapasitesi ve fonksiyonel kapasite ile ilişkilidir [27]. Kas zayıflığı KOAH'l yaşlılarda kısır döngü halinde fonksiyonel kapasitede azalmalara, fonksiyonel limitastonlara ve günlük yaşam aktivitelerinde zorluklar yaşanmasına sebep olmaktadır. $\mathrm{Bu}$ nedenle standart bir PR program1, alt ve üst ekstremitelerin kas gücü ve dayanıklılığını artıran aerobik egzersizleri içerir. Aerobik egzersizler genellikle yürüme, bisiklet ergometresi, koşu bandı egzersizleri ve solunum egzersizleri ile kombine olarak yapılan üst ekstremite egzersizleri olarak programa dahil edilmektedir $[23,26,28]$. Boxal ve ark. 46 KOAH'lı yaşlı üzerinde yapmış olduğu çalışmada 10 aşamalı aerobik egzersiz ve üst extremiteye yönelik kuvvetlendirmeyi içeren 12 haftalık PR programının algılanan dispne hissini azalttığını, egzersiz toleransını ve günlük yaşam aktivitelerine katılımı arttırdığını tespit etmiştir [28]. Sundararajan ve arkadaşlarının çalışmasında alt ve üst ekstremiteye yönelik uygulanan endurans egzersizlerini içeren 6 haftalık PR programı sonrasında hastaların dispne skorlarında azalma, yürüme mesafelerinde ve yaşam kalitelerinde artış gözlenmiştir [25]. Üst ve alt extremitelere yapılan endurans egzersizlerine ek olarak inspiratuar kas eğitimini içeren başka bir çalışmada PR'nin kronik hipoksemi varlığında bile yürüme mesafesini ve FEV1/ FVC değerlerini arttırdığını göstermiştir [29].

İnspiratuar kas eğitimi (İMT) ve ekspiratuar kas eğitimi (EMT) solunum kas gücünü artırmak ve dispne hissini azaltmak için KOAH tedavisinde yaygın olarak kullanılmaktadır. Yapılan çalışmalarda İMT ve EMT kas eğitiminin solunum fonksiyon testleri, solunum kas kuvveti, oksijenasyon ve yürüme mesafesinde artış sağlamak için pulmoner rehabilitasyon programlarına eklenmesi gerektiği belirtilmektedir [29,30]. Bu eğitimlerde dozajın maksimum inspiratuar basıncın $\% 10$ 'unda düşük yoğunlukla başlatılıp kademeli olarak \%60'a kadar arttırılması önerilmektedir. Bu yoğunluğu tolere edemeyen hastalarda ise eğitimin etkin olması için en az maksimum inspiratuar basıncın \%30'u ile eğitim verilmesi gerektiği bildirilmektedir. IMT ve EMT kas eğitimini karşılaştıran ve 40 yaşlının katılımıyla yapılan bir çalışmada her iki grupta tüm değerlendirme parametrelerinde (solunum fonksiyon testi, 6 dakika yürüme testi, solunum kas kuvveti) anlamlı gelişmeler olduğu bildirilmiştir. İMT eğitim grubunda kan gazı analizinde, EMT eğitim grubunda 6 dakika yürüme testinde daha iyi sonuçlar alındığı tespit edilmiştir [30]. PR programının en önemli bileşenlerinden biri olan diyafragmatik solunum; KOAH'lı yaşlılarda hastalık yönetimi için öğretilen bir solunum stratejisidir. Solunum ihtiyacını en aza indirmek, solunum koordinasyonunu ve 
inspiratuar kas kuvvetini arttırmak, öksürme sıklığını, dispneyi ve hipoksemi semptomlarını azaltmak ve balgam klirensini kolaylaştırmak amaciyla PR programının bir parçası olarak uygulanmaktadır [23,31,32]. 4 dakika doğal solunumu takiben 2 dakika fizyoterapist tarafindan abdominal bölgeye taktil uyarı verilerek yapılan diyafragmatik solunum egzersizinin solunum paternini geliştirdiği ve ventilatuar etkinliği arttırdığ 1 bildirilmiştir [32].

$\mathrm{KOAH}$, dispne ve kas zayıflığı gibi fonksiyonel eksikliğe neden olabilir. Bu nedenle dirençli egzersiz; kas kuvveti, sağlık ve yaşam kalitesini artırmak için çok önemlidir ve KOAH'lı yaşlılarda PR programına dahil edilmektedir [33,34]. Dirençli egzersizler genellikle göğüs kasları, omuz bölgesi, kol, sırt- abdominal kasları ve quadriseps femoris ve gastro- soleus kaslarını içerir [33]. Bir maksimum tekrarın \%35'i ile başlayıp \%75'ine kadar çıkılan, haftada 2 gün, 20 set ve 2 tekrar şeklinde 3 ay süren kuvvetlendirme programının KOAH'lı yaşlılarda egzersiz kapasitesi, kas kitlesi ve yaşam kalitesini arttırdığı belirlenmiştir [34].

KOAH'lı yaşlı bireylerde fiziksel aktivite düzeyleri, sağlıklı kontrollere kıyasla önemli ölçüde azalmaktadır. İnaktivite; akciğer fonksiyonu, kas kütlesi, egzersiz toleransı ve mortalite üzerinde olumsuz etkilere sahiptir. Yapılan çalışmalarda pulmoner fonksiyon, dispne, vücut kompozisyonu, ekstra pulmoner fonksiyon ve sağllk durumunun KOAH'ta fiziksel aktivite düzeyi ile anlamlı düzeyde ilişkili olduğu, aynı zamanda KOAH şiddeti arttıkça, fiziksel aktivite süresi ve periyotlarının azaldığı rapor edilmiştir [35,36]. Bu nedenle KOAH'lı yaşlılar mutlaka fiziksel aktiviteye yönlendirilmelidir. Iwakura ve arkadaşlarının çalışmasında fiziksel aktivite düzeyinin KOAH'lı yaşlılarda düşük olduğu ve fiziksel aktivite yetersizliğinin denge parametreleriyle negatif yönde ilişkili olduğu belirtilmiştir [36]. PR programına ek olarak akselerometre ile fiziksel aktivitenin teşvik edildiği başka bir çalışmada düşük yoğunluklu PR programının fiziksel aktiviteyi arttırdığ 1 , akselerometre kullanımının daha fazla fiziksel aktiviteyi teşvik ettiği tespit edilmiştir [31]. Amerikan Spor Hekimliği Koleji ve Amerikan Kalp Derneği yaşlı bireylerin haftada 5 gün en az 30 dakika orta yoğunlukta veya haftada 3 gün en az 20 dakika şiddetli yoğunlukta aerobik fiziksel aktivite yapmalarını tavsiye etmektedir [37]. Mevcut fiziksel aktivite yönergeleri, fiziksel aktivite önerilerinin hastaların ihtiyaçları, hedefleri ve yetenekleri göz önüne alınarak düzenlenmesi yönündedir. Dolayısıyla ardışık 30 dakika fiziksel aktivite KOAH'lı yaşlılarda her biri en az 10 dakika sürecek şekilde veya iki set halinde yapılabilir. Aktivite sınırlamaları göz önüne alındığında bu adaptasyon KOAH'lı yaşlılar için daha faydalı olacaktır [35].

Yaşlılarda KOAH prognozunu etkileyen önemli etmenlerden biri de yaygın geriatrik sendromlardır. $\mathrm{Bu}$ sendromların KOAH'a eşlik etmesi egzersiz kapasitesinde, fiziksel aktivite seviyelerinde ve yaşam kalitesinde düşüşlere neden olmaktadır. $\mathrm{Bu}$ nedenle $\mathrm{KOAH}$ tedavisi aynı zamanda bu sendomların tedavisi anlamına da gelmektedir [17,20]. Jones ve ark. yapmış oldukları çalışmada sarkopenik olmanın PR'ye cevabı etkilemediğini; 43 KOAH'lı sarkopenik hastanın 12'sinin 8 haftalık PR sonrası artık sarkopenik olarak sınıflandırılmadığını tespit etmiştir [17]. Sarkopenik ve kırılgan yaşlıların PR'ye cevabını araştıran bir sistematik derlemede ise, pulmoner rehabilitasyonun bu hasta grubunda etkin olduğu ve kırılgan yaşlıların \% 61'inin PR programının tamamlanmasından sonra artık kırılganlık kriterlerini taşımadığını vurgulamıştır [38].

PR programının akut alevlenme döneminde etkili olduğu ve hastanede yatıș süresini ve nüksleri önlediği belirtilmektedir [23,39]. Liao ve arkadaşlarının çalışmasında; egzersiz grubuna hava yolu temizleme teknikleri, büzük dudak solunumu, solunum egzersizleri ile kombine olarak uygulanan üst ekstremite egzersizleri ve yürüme programını içeren PR programı uygulanmıştır. Sonuç olarak katılımcıların öksürük ve dispne şikayetleri belirgin düzeyde azalmış ve egzersiz toleransında artış görülmüştür [23]. Akut alevlenme yaşayan hastalarda yapılan bir başka çalışmanın sonuçları da PR'nin 3 aylık süre içinde yeniden alevlenme görülme sıklığını azalttığını göstermektedir [39].

\section{Sonuç}

Sonuç olarak KOAH'lı yaşlılarda PR uzun dönem pulmoner fonksiyonlar ve fonksiyonellik üzerinde pozitif terapötik etkiye sahiptir. PR yaşlılarda KOAH yönetiminin önemli bir parçasını oluşturmaktadır. Yaşlılarda standart bir PR programı olmamakla beraber; aerobik egzersiz, diafragmatik solunum, direnç egzersizleri, inspiratuar ve ekspiratuar kas eğitimi PR programının bileşenlerini oluşturmaktadır. Literatürde bu egzersizlerin yaşlılarda KOAH semptomlarının azaltılmasında, pulmoner fonksiyonların ve egzersiz toleransının artırılmasında etkin olduğu kanıtlanmıştır. Yaşlilarda PR'nin etkileri gençlerle benzer olup yaş PR için dışlama kriteri değildir. Yaşlılık döneminde yaygın olarak görülen kırılganlık ve sarkopeni varlığında bile PR etkindir. $\mathrm{Bu}$ nedenle $\mathrm{KOAH}$ tanılı hastalarda yaşa ve eşlik eden problemlere bakılmaksızın medikal tedavi ile birlikte PR mutlaka uygulanmalıdır. Yaşlı bireylerde PR programında öncelikli olarak dikkat edilmesi gereken nokta yaş grubuna uygun dozajda egzersiz ve fiziksel aktivite önerilerinin verilmesidir. Ayrıca KOAH'lı yaşlılarda kas kuvveti, fiziksel aktivite ve egzersiz kapasitesindeki azalmalara bağlı olarak, yaşlılarda mortalitenin önemli belirleyicilerinden biri olan denge kaybı meydana gelebileceğinden KOAH'lı yaşlılarda denge değerlendirme ve tedavisini içeren çalışmaların yapılması gerektiği düşünülmektedir.

\section{Referanslar}

1. Cortopassi, F, Gurung P, Pinto-Plata, V, Chronic Obstructive Pulmonary Disease in Elderly Patients, Clinics in Geriatric Medicine, 2017, 33(4), 539-52.

2. Kim, E.J, Yoon, S.J, Kim, Y.E, Go, D.S, Jung, Y, Effects of aging and smoking duration on cigarette smoke-induced COPD severity, Journal of Korean Medical Science, 2019, 34, 1-7.

3.Crisafulli, E, Morandi, A, Olivini, A, Malerba, M, Clin,i E.M, Rehabilitation and supportive therapy in elderly patients with chronic obstructive pulmonary disease, European Journal of Internal Medicine, 2014, 25(4), 329-35. 
4. Adeloye, D, Chua, S, Lee, C, Basquill, C, Papana, A, Theodoratou, $\mathrm{E}$, et al., Global and regional estimates of COPD prevalence: Systematic review and meta-analysis, In: Journal of Global Health, 2015, 5(2) p. 020415.

5. Kocabaş, A, Atış, S, Çöplü, L, Erdinç,, E, Ergan B, Gürgün, A, et al., Türk Toraks Derneği KOAH Çalıșma Grubu kronik obstrüktif akciğer hastalığı (KOAH) koruma, tanı ve tedavi raporu 2014 Turkish Thoracic Journal, 2014, 15.

6. Coates, J, Potal, I.C.R, West, J.B, et al., The lung: scientific foundations vol.2. 2nd ed, Philadelphia, 1997, 2193-203. p.

7. Divo, M, Cote, C, de Torres, J.P, Casanova, C, Marin, J.M, PintoPlata, V, et al., Comorbidities and Risk of Mortality in Patients with Chronic Obstructive Pulmonary Disease, American Journal of Respiratory Critical Care Medicine, 2012, 186(2), 155-61.

8. Shweta, P, Kukrety, Jai D. Parekh, K.L.B, Chronic obstructive pulmonary disease and the hallmarks of aging, Lung India, 2018 , 35(4):1-2

9. Gold 2017 global strategy for the diagnosis, management and prevention of copd, 2019.

10. Kocabaş, A. KOAH epidemiyolojisi ve risk faktörleri, Türk Toraks Derneği Toraks Cerrahisi Bülteni, 2010, 1(2), 105-13.

11. Marcus, B.S, McAvay, G, Gill, T.M, Vaz Fragoso, C.A. Respiratory symptoms, spirometric respiratory impairment, and respiratory disease in middle-aged and older persons, Journal of American Geriatric Society, 2015, 63(2), 251-7.

12. Vollmer, W.M, Gíslason, P, Burney, P, Enrigh, P.L, Gulsvik, A Kocabas, A, et al, Comparison of spirometry criteria for the diagnosis of COPD: Results from the BOLD study, European Respiratory Journal, 2009, 34(3), 588-97.

13. Hardie, J.A, Buist. A.S, Vollmer, W.M, Ellingsen, I, Bakke, P.S Mørkve, O, Risk of over-diagnosis of COPD in asymptomatic elderly never-smokers, European Respiratory Journal, 2002, 20(5), 1117 22.

14. Shirtcliffe, P, Weatherall, M, Marsh, S, Travers, J, Hansell, A, Mcnaughton, A, et al., COPD prevalence in a random population survey : a matter of definition study subjects, European Respiratory Journal, 2008, 30(2):232-9.

15. Allen, S.C, Warwick-Sanders, M, Baxter, M,, A comparison of four tests of cognition as predictors of inability to learn to use a metered dose inhaler in old age, International Journal of Clinical Practice, 2009, 63(8), 1150-3.

16. Taffet, G.E, Donohue, J.F, Altman, P.R, Considerations for managing chronic obstructive pulmonary disease in the elderly, Clinical Interventions in Aging, 2014, 9, 23-30.

17. Jones, S.E, Maddocks, M, Kon, S.S.C, Canavan, J.L, Nolan, C.M Clark, A.L, et al., Sarcopenia in copd: Prevalence, clinical correlates and response to pulmonary rehabilitation, Thorax, 2015, 70(3), 2138.

18. Munhoz da Rocha Lemos Costa,T, Marcelo Costa, F, Aguia Moreira, C, Maria Rabelo, L, Luiz Boguszewski, C, Sarcopenia in COPD: relationship with COPD severity and prognosis, Jornal Brasileiro de Pneumologia, 2015, 41(5), 415-21.

19. Lahousse, L, Ziere, G, Verlinden, V.J.A, Zillikens, M.C, Uitterlinden A.G, Rivadeneira, F, et al, Risk of Frailty in Elderly With COPD: A Population-Based Study, The Journals of Gerontology Series A Biological Sciences and Medical Sciences, 2016, 71(5), 689-95.

20. Guan, C, Niu, H, Frailty assessment in older adults with chronic obstructive respiratory diseases, Clinical Interventions in Aging, $2018,13,1513-24$

21. Wongsurakiat, P, Maranetra, K.N, Wasi, C, Kositanont,, U, Dejsomritrutai W, Charoenratanakul, S. Acute respiratory illness in patients with COPD and the effectiveness of influenza vaccination: A randomized controlled study, Chest, 2004, 125(6), 2011-20.

22. Dimitrova, A, Lubenova, D, Grigorova-Petrova, K, Maznev, I, The effectiveness of long term physical therapy in elderly patients with chronic obstructive pulmonary disease, European Respiratory Journal, 2016, 48(PA 684)

23. Liao, L.Y, Chen, K.M, Chung, W.S, Chien, J.Y, Efficacy of a respiratory rehabilitation exercise training package in hospitalized elderly patients with acute exacerbation of COPD: A randomized control trial, International Journal of COPD, 2015, 10(1), 1703-9.

24. Rochester, C.L, Vogiatzis, I, Holland, A.E, Lareau, S.C, Marciniuk DD, Puhan, M.A, et al., An official American Thoracic
Society/European Respiratory Society policy statement: Enhancing implementation, use, and delivery of pulmonary rehabilitation, American Journal of Respiratory Critical Care Medicine, 2015, 192(11), 1373-86.

25. Sundararajan, L, Balami, J, Packham, S, Effectiveness of outpatien pulmonary rehabilitation in elderly patients with chronic obstructive pulmonary disease, Journal of Cardiopulmonary Rehabilitation and Prevention, 2010, 30(2), 121-5.

26. Yang, S, He, Y, Wan,g J, Liu, M, Jiang, B, Smoking cessation protects against COPD in an elderly population, International Journal of Clinical and Experimental Medicine, 2018, 11(8), 862833

27. Singer, J, Yelin, E.H, Katz, P.P, Sanchez, G, Iribarren, C, Eisner, M.D, et al, Respiratory and skeletal muscle strength in chronic obstructive pulmonary disease: Impact on exercise capacity and lower extremity function, Journal of Cardiopulmonary Rehabilitation and Prevention, 2011, 31(2), 111-9.

28. Boxall, A.M, Hons, P.H, Barclay, L, Allyn Sayers, R.N, Caplan, G, Managing chronic obstructive pulmonary disease in the community setting, British Journal of Community Nursing, 2018, 23(1), 6-12.

29. Di Meo, F, Pedone, C, Lubich, S, Pizzoli, C, Traballesi, M, Incalzi, RA, Age does not hamper the response to pulmonary rehabilitation of COPD patients, Age Ageing, 2008, 37(5), 530-5.

30. Mehani, S.H.M, Comparative study of two different respiratory training protocols in elderly patients with chronic obstructive pulmonary disease, Clinical Interventions in Aging, 2017, 12, 170515

31. Kawagoshi, A, Kiyokawa, N, Sugawara, K, Takahashi, H, Sakata, S Satake, M, et al, Effects of low-intensity exercise and home-based pulmonary rehabilitation with pedometer feedback on physical activity in elderly patients with chronic obstructive pulmonary disease, Respiratory Medicine, 2015, 109(3), 364-71.

32. Fernandes, M, Cukier, A, Feltrim, MIZ, Efficacy of diaphragmatic breathing in patients with chronic obstructive pulmonary disease, Chronic Respiratory Disease, 2011, 8(4), 237-44.

33. Cameron-Tucker, H.L, Wood-Baker, R, Owen, C, Joseph, L, Walters, E.H, Chronic disease self-management and exercise in COPD as pulmonary rehabilitation: A randomized controlled trial, International Journal of COPD, 2014, 9, 513-23.

34. Boeselt, T, Nell, C, Lütteken, L, Kehr, K, Koepke,, J, Apelt S, et al, Benefits of High-Intensity Exercise Training to Patients with Chronic Obstructive Pulmonary Disease: A Controlled Study, Respiration, 2017, 93(5), 301-10.

35. Donaire-Gonzalez, D, Gimeno-Santos, E, Balcells,, E, Rodríguez D.A, Farrero, E, De Batlle, J, et al, Physical activity in COPD patients: Patterns and bouts, European Respiratory Journal, 2013, 42(4), 993-1002.

36. Iwakura, M, Okura, K, Shibata, K, Kawagoshi, A, Sugawara, K, Takahashi, H, et al, Relationship between balance and physical activity measured by an activity monitor in elderly COPD patients, International Journal of COPD, 2016, 11(1), 1505-14.

37. Nelson, M.E, Rejeski, W.J, Blair, S.N, Duncan, P.W, Judge, J.O, King, A.C, et al, Physical activity and public health in older adults Recommendation from the American College of Sports Medicine and the American Heart Association, Medicine and Science in Sports and Exercise, 2007, 39(8): 1435-45.

38. Attwell, L, Vassallo, M, Response to pulmonary rehabilitation in older people with physical frailty, sarcopenia and chronic lung disease, Geriatrics, 2017, 2(1), 5-11.

39. Seymour, J.M, Moore, L, Jolley, C.J, Ward, K, Creasey, J, Steier, J.S et al, Outpatient pulmonary rehabilitation following acute exacerbations of COPD, Thorax, 2010, 65(5), 423-8.

http://edergi.cbu.edu.tr/ojs/index.php/cbusbed isimli yazarın CBU-SBED başlıklı eseri bu Creative Commons Alıntı-Gayriticari4.0 Uluslararası Lisansı ile lisanslanmıștır.

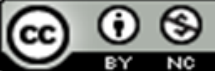

